\section{Violência e sofrimento social no itinerário de travestis de Santa Maria, Rio Grande do Sul, Brasil}

\author{
Violence and social distress among transgender \\ persons in Santa Maria, Rio Grande \\ do Sul State, Brazil
}

\section{La violencia y el sufrimiento social en el itinerario de las personas transgénero de Santa María, Río Grande do Sul, Brasil}

Martha Helena Teixeira de Souza 1

Paulo Malvasi 2

Marcos Claudio Signorelli 3

Pedro Paulo Gomes Pereira 4

\footnotetext{
${ }^{1}$ Centro Universitário Franciscano, Santa Maria, Brasil.

2 Universidade Anhanguera de São Paulo, São Paulo,

Brasil.

3 Universidade Federal do

Paraná, Curitiba, Brasil.

4 Universidade Federal de

São Paulo, São Paulo, Brasil.

Correspondência

M. H. T. Souza

Centro Universitário

Franciscano.

Rua Irmã Rosália 47, Santa

Maria, $R S$

97060-267, Brasil.

marthahts@gmail.com
}

\begin{abstract}
The authors conducted an ethnographic research with transgender persons in Santa Maria, Rio Grande do Sul State, Brazil, in 2012, using participant observation, semi-structured interviews, and following their everyday lives. These individuals invariably experienced physical and symbolic violence and the resulting distress, a condition they had to deal with in their careers and daily practices and tasks. The article discusses the violence experienced by transves tites (in the family, school, police precincts, and health services), specifically seeking to understand how such violence relates to their experiences with health services and how the latter respond.
\end{abstract}

Travestism; Violence; Homophobia

\section{Resumo}

No ano de 2012, realizamos pesquisa etnográfica com travestis de Santa Maria, Rio Grande do Sul, Brasil, por meio de observação participante, entrevistas e acompanhamento de suas vidas cotidianas. Durante esse período, percebemos que as violências física e simbólica e o sofrimento delas decorrentes eram invariantes, condição com a qual tinham que lidar em seus itinerários, em suas práticas e afazeres diários. Este artigo discute as violências vivenciadas nas trajetórias percorridas pelas travestis (família, escola, delegacias, serviços de saúde), procurando, sobretudo, compreender como tais violências estão relacionadas às experiências nos serviços de saúde e como os serviços de saúde por elas acessados reagiram às violências.

Travestismo; Violência; Homofobia 


\section{Introdução}

As análises sobre violência vêm se multiplicando e elucidando dimensões importantes da violência contra crianças, adolescentes, mulheres e idosos, inclusive, influenciando documentos importantes, tais como o Estatuto da Criança e do Adolescente (ECA), a Lei Maria da Penha e o Estatuto do Idoso. O tema violência entrou com mais vigor na agenda da saúde no Brasil, na década de 1980, e, a partir de 1990, a Organização Pan-Americana da Saúde (OPAS) e a Organização Mundial da Saúde (OMS) incluíram especificamente a violência no endereçamento das políticas públicas da saúde. Os reflexos da violência na saúde da população mundial e brasileira vêm sendo estudados por diversos autores 1,2,3,4. Acompanhando o movimento desses autores, este artigo pretende discutir a violência contra travestis - tema que, apesar de alguns meritórios esforços, ainda tem recebido pouca atenção da academia, das organizações da sociedade civil e dos governos.

No campo da saúde coletiva, a noção de violência recebe um tratamento abrangente, sendo abordada como um conjunto que envolve: a possibilidade ou a ameaça potencial de uso da força física; os abusos nas relações entre grupos sociais; a opressão e o abandono de segmentos populacionais; e o abalo causado por torturas físicas e emocionais 5 . São acontecimentos que manifestam as tensões presentes em todas as sociedades humanas. Com efeito, a violência é um fenômeno de causalidade complexa, que envolve diversas dimensões da experiência humana. Tal fenômeno ganha contornos decisivos na contemporaneidade, pois dramatiza causas emergentes e as situa no debate público. Embora não seja um problema específico da área de saúde, a violência, no entanto, afeta diretamente a saúde 5,6 .

Em 2012, pela primeira vez no Brasil, foram divulgados dados oficiais sobre as violações de Direitos Humanos da população de lésbicas, gays, bissexuais, travestis e transexuais (LGBT), reportadas ao Poder Público Federal por meio do Relatório sobre Violência Homofóbica no Brasil, Ano de 2011. Os dados desse relatório apontaram que o número de homicídios de pessoas LGBT no Brasil aumentou 11,51\% de 2011 para 2012. Os resultados também apontaram que travestis e transexuais seguem sendo as maiores vítimas de violência homofóbica e das violências de maior gravidade, como homicídios e lesões corporais 7 . Autores 8,9,10,11,12,13 que desenvolvem pesquisas a respeito da hostilidade contra a população LGBT mostraram que a violência que atinge travestis, sobretudo as que atuam como profissionais do sexo, é mais agressiva do que a que tende a vitimar outros homossexuais, particularmente os que não exibem os sinais de diferença no corpo.

A pesquisa que realizamos mostrou que, nos itinerários das travestis, a violência é constante e ocorre de múltiplas formas, inclusive nos serviços de saúde. Entendemos itinerário como os diversos caminhos percorridos pelas pessoas (sujeitos que edificam trajetórias por espaços, lugares, instâncias, instituições). Dadas as dimensões da violência nas experiências, no caso das travestis, uma parcela significativa dos itinerários é a busca por cuidados, ou seja, os tortuosos caminhos percorridos pelas pessoas na tentativa de adequar seu corpo e de solucionar agravos, incluindo os problemas de saúde 14,15,16.

Neste artigo, não há o reconhecimento de um conceito unívoco de violência; antes, a nossa intenção foi verificar como nossas interlocutoras definiam violência, considerando situações que envolvem agressões que o destinatário preferiria não sofrer 17. A abordagem não parte de um conceito de violência, mas busca destacar a violência nas narrativas de agressões físicas e psicológicas sofridas pelas travestis em seus itinerários; agressões que compõem relatos de sofrimento gerados pela escolha e pela condição de ser travesti. Consideramos, portanto, a violência sofrida pelas travestis no seio de dinâmicas sociais marcadas por relações de poder, que caracterizam a experiência das participantes do estudo com instituições que reproduzem uma ordem social heteronormativa. Neste artigo, discutimos, então, as violências vivenciadas nas trajetórias percorridas pelas travestis, destacando-se contextos da família, escola, delegacias e serviços de saúde.

\section{Metodologia}

Baseamos este trabalho em metodologia qualitativa de estudo, por meio de proposta de pesquisa etnográfica, na qual foram adotados procedimentos de observação participante, entrevistas em profundidade e acompanhamento da vida cotidiana das interlocutoras. Trata-se, portanto, de uma pesquisa qualitativa que buscou se aproximar do fazer etnográfico, procurando, acima de tudo, as concepções das interlocutoras sobre a violência, tentando compreender a própria compreensão das travestis de Santa Maria, Rio Grande do Sul, Brasil, sobre violência. A opção pela investigação etnográfica deveu-se à sua relevância e à atualidade nas pesquisas em saúde 18,19. Etnografia não é definida pelas técnicas que emprega, como observação participante e entrevistas, mas, por um tipo particular de esforço de "descrição densa” 20. Essa descrição, obtida por meio 
de imersão na vida diária do grupo pesquisado, focaliza detalhes e informações subjacentes, almejando explicar modos de vida e descrevendo padrões de significado que informam as ações sociais, assim como os tornam acessíveis. $\mathrm{Na}$ pesquisa etnográfica, a proximidade permite um olhar sobre o microcosmo de relações humanas. Cabe ressaltar que a pesquisa teve uma orientação etnográfica, e, por uma opção na construção deste artigo, aqui, privilegiamos as análises dos depoimentos das interlocutoras.

A descrição das causas externas que impactam na saúde amiúde não revela algumas das complexas teias de significados construídas em torno da violência e, assim, dificulta a compreensão das experiências humanas em que a violência ocorre 21. Portanto, defendemos a utilização de métodos qualitativos, como a aproximação etnográfica adotada neste estudo, para compreender essa complexa tessitura.

Realizamos a pesquisa de campo no período de janeiro a novembro de 2012, em distintos momentos ao longo da semana e nos fins de semana, e também em diferentes horários, inclusive durante a noite e nas madrugadas. Acompanhamos, ao longo da pesquisa, 49 travestis residentes no Município de Santa Maria. Durante esse período, participamos intensamente das atividades das travestis: festas, encontros, eventos por elas promovidos, atividades nas casas de algumas travestis e nas pensões em que vivem. Estivemos com as travestis em suas residências, quando com a família nuclear, e nas pensões; nos diversos serviços de saúde (unidades básicas de saúde - UBS, hospitais); fomos chamados em casos de violência e, sempre seguindo nossas interlocutoras, fomos à delegacia; quando da busca de transformação corporal, permanecemos com as travestis nas sessões com "bombadeiras"; à noite, fomos às festas, às casas de santo, às reuniões e mesmo na "pista". Enfim, procuramos seguir nossas interlocutoras em seus diversos e intricados caminhos.

O contato da autora principal deste estudo com as interlocutoras data desde as ações de prevenção das DST/AIDS promovidas inicialmente na Secretaria Municipal de Saúde de Santa Maria, no ano de 1996, e, na sequência, no projeto AIDS II, no Consórcio Intermunicipal de Saúde (1999/2008). A partir desse contato inicial com o grupo de travestis, as demais participantes do estudo foram sendo indicadas pelas próprias travestis. Fomos inspirados aqui na técnica "snowball sampling" ou "bola de neve" 22. Essa estratégia é adotada em pesquisas qualitativas e consiste na indicação, pelos participantes iniciais de um estudo, de novos participantes que, por sua vez, indicam outros participantes e assim suces- sivamente. Desse modo, estabelece-se uma rede de interlocutores até que seja alcançado o objetivo proposto pelo estudo, denominado de "ponto de saturação". Tal ponto é atingido quando novos entrevistados passam a repetir os conteúdos já obtidos em entrevistas anteriores, sem acrescentar dados relevantes à pesquisa 22 .

As observações e narrativas que emergiram do campo foram transcritas, codificadas, categorizadas tematicamente e cotejadas com acepções teóricas dos estudos de gênero, de violência e do campo da saúde coletiva no que tange às principais repercussões da violência nos itinerários vivenciados pelas travestis. Para escrever a etnografia, é significativo que o pesquisador se aproprie dos dados coletados em campo, dando um sentido às suas experiências 20 . Como categorias emergentes neste estudo, destacaram-se: (1) violência e sofrimento social na família; (2) na escola; (3) na delegacia; e (4) nos serviços de saúde, que serão detalhadas na seção de resultados.

$\mathrm{O}$ anonimato e confidencialidade das interlocutoras foram garantidos, sendo adotados pseudônimos. Informamos todas as participantes sobre os objetivos do estudo, e elas assinaram o Termo de Consentimento Livre e Esclarecido, sendo que esta proposta seguiu todos os procedimentos éticos, tendo sido aprovada pelo Comitê de Ética em Pesquisa da Universidade Federal de São Paulo (UNIFESP, processo 1937/11).

\section{Resultados e discussão}

Na região central do Rio Grande do Sul, localizase Santa Maria, município brasileiro com 270 mil habitantes, onde residiam as travestis no período de realização desta pesquisa. As travestis são provenientes de pequenas cidades do interior do estado, além de Santa Maria, com idade entre 18 e 53 anos e Ensino Fundamental incompleto. A maioria divide aluguel com outras travestis, espaços nos quais se identificam por "manas" - sendo uma constante o perambular na região pela busca dos "pensionatos". A saída precoce da família nuclear é uma das justificativas para a procura de parcerias das "manas". Com relação à atividade laboral, três participantes desta pesquisa atuam como mães de santo, uma como pai de santo, duas são diaristas, uma realiza serviços gerais na rodoviária e as demais são profissionais do sexo. É habitual, na busca por desviar situações que geram constrangimento, evitarem os espaços públicos, como a rua durante o dia, e outros locais comuns, como a farmácia, o mercado, a padaria, entre outros.

Desde o início do trabalho de campo, observamos claramente a exposição a situações de 
violência física como uma constante no cotidiano das travestis que, agredidas e feridas, como demonstraremos no decorrer deste artigo, encontram, no atendimento nos serviços de saúde e nas delegacias de polícia, uma extensão dessa mesma violência. As travestis são também vítimas de ofensas verbais em diferentes contextos, como família, escola, pontos de prostituição e espaços públicos. As narrativas de nossas interlocutoras descrevem processos que, atuando contra a diferença dos corpos das travestis, implementam e naturalizam a violência nas famílias, nas escolas, nas delegacias e nos serviços de saúde. As narrativas das travestis fazem referência a violências que perpassam suas trajetórias, indicando um contexto que percebem como violento. Na realidade, a violência se expressa como fenômeno que ocorre não em momentos excepcionais, mas, como parte constituinte das vidas - a violência como fenômeno ubíquo, perpassando diversas esferas da vida das travestis. Vamos acompanhar então o itinerário dessas nossas interlocutoras, pela família, escola, delegacias e serviços de saúde.

\section{Família}

Das 49 travestis que participaram deste estudo, todas relataram ter vivenciado situações de agressão física e xingamentos em diferentes contextos e locais. Pelos relatos das interlocutoras, percebe-se que as agressões se iniciam no contexto da família nuclear e têm seguimento no ambiente escolar, fazendo com que abandonem esses espaços, formando novas "famílias" constituídas exclusivamente por travestis. Essas novas famílias são, em certa medida, formas de lidar com a violência e com o sofrimento dela decorrente.

Após situações que envolvem a expulsão ou mesmo a rejeição da família de origem e a dificuldade de localizar moradia como qualquer outro cidadão, as pensões de travestis tornam-se os locais, quase exclusivos, onde elas são aceitas. Ao buscarem formar "casas" de convivência entre travestis, elas criam novos laços, muitas vezes, ampliando a noção de família: ali elas constroem relações de afeto, sendo identificadas por "manas" 23.

As travestis vivenciam situações de opressão e discriminação desde quando suas escolhas e mudanças corporais começam a se tornar conhecidas. A descoberta da sexualidade é o momento no qual convivem com surras, insultos e diversos tipos de rejeição familiar. Não estar nos padrões de gênero esperados pela família é um dos primeiros obstáculos vivenciados pelas travestis, como observou Charlenne, 26 anos:
"A maioria [das travestis] tem histórias tristes na família. Sempre teve um pai, um irmão, um tio, que xingou, bateu e expulsou a travesti de casa. $́$ só começar a transformar o corpo que as coisas pioram para o nosso lado".

Como muitas histórias que ouvimos durante a pesquisa, a de Victoria, 18 anos, também ressaltou, em julho de 2012, a associação entre transformação corporal e início da violência na família:

"Quando comecei a ingerir hormônios e usar roupas femininas, minha mãe foi embora, abandonou a família. Meu pai ficou morando nos fundos da casa dos meus avós, mas sempre que chegava bêbado, me dava uma surra. E meus avós, até me aceitam, mas não querem que eu tome remédios para ficar feminina. Preferiam quando eu era neto, mas não me querem como neta. Dizem que isso é pura sem-vergonhice. Fico pensando em que lugar vou morar se não tenho emprego e não consigo pagar um aluguel. Ouço piadas na escola e tento não dar muita atenção, pois, se parar de estudar, vai ser mais difícil ainda para arrumar emprego depois".

Quando a travesti resolve assumir seu processo de feminilização, comumente, afasta-se da família e da escola. No caso dos meninos e adolescentes gays, travestis e lésbicas, é dentro de casa e na própria família que o preconceito e a discriminação assumem características de crueldade, incluindo insultos, tratamentos compulsórios, humilhação, agressão física e até a expulsão do lar 24 .

A violência perpetrada pela família é uma das situações que as travestis evitam falar. A maioria demonstrou desconforto ao falar de avós, pais e irmãos. Em muitos casos, não conseguiram transformar o sentimento em discurso, e o silêncio sobre essa discriminação em suas próprias famílias de origem tornou-se um importante dado da pesquisa. A intuição de que determinados abusos não podem ser verbalizados na vida cotidiana está no reconhecimento de que não se pode trabalhá-los no âmbito do cotidiano 25 . Essa violência traz à tona aquilo que constitui o não-narrativo da violência: o que é indizível nas formas da vida cotidiana.

Quando as travestis precariamente conseguem falar sobre o tema, costumam confessar que um dos momentos de maior tensão nas relações com seus familiares é o da "revelação" aos pais. Os conflitos se agravam quando as travestis se assumem e se "montam" 26. Após anos de sofrimento, no período em que o desejo de começar as modificações no corpo se evidencia, não há mais como esconder-se atrás de uma heterossexualidade desejada pelos familiares. Tampouco há como simular uma homossexualidade 
que, no dizer de algumas travestis, implicaria em menor violência na família. Thalya, 24 anos, tentando resumir as diferenças entre esses dois quadros, salienta que é comum o pai dizer: " $u m$ filho gay até engulo, mas travesti, nunca!”. Situações de rejeição são evidenciadas, na maioria das vezes, por parte do pai, conforme revela a fala de Penélope, 23 anos:

"Meu pai só voltou a falar comigo poucos dias antes de falecer. Já faz dois anos que o meu pai faleceu. Na verdade, toda a minha família tinha dificuldade de aceitar, mas meu pai sempre foi pior, ele sempre me batia muito".

Em alguns casos, a violência sofrida no espaço familiar pode ser tamanha que leva ao desejo de suicídio, como salientou Stelly, 32 anos:

"Eu já tentei me matar algumas vezes. No início, foi muito difícil. E não sou a única que tem essa história de querer morrer. E depois, buscar um tratamento na saúde porque ficamos deprimidas é difícil, porque as pessoas acham que, se queremos ser travestis, o azar é nosso. Então, para não adoecer, a gente busca outras formas de não se deprimir. Tentamos levar tudo na brincadeira, travesti geralmente é muito divertida, faz piada de tudo".

As primeiras experiências de rejeição na família, vivenciadas pelas travestis, dão início a um processo de enfraquecimento da autoestima 9 . Essa fragilidade pode torná-las, inicialmente, confusas e desorientadas, sendo esse o momento em que o sentimento de pertença leva à aproximação de pessoas que coadunam de mesmos gostos, desejos, sonhos, pessoas que, de certa forma, compartilham suas experiências, necessidades, desejos e projetos 9 .

\section{A escola}

A escola é outro espaço em que violência e sofrimento conformam as experiências das travestis. Tefhy, 38 anos, narrou, em agosto de 2012, uma história dramática de quando era "um menino no pátio da escola":

“Na escola, não era só eu que percebia ser diferente. Todos os meninos também notavam. Quando eu tinha uns 12 anos, resolveram arrancar minhas roupas no pátio, na hora do recreio, na frente de todos. Minha mãe foi na escola para saber o que havia acontecido. Então, depois disso, meus pais me colocaram em uma academia para eu ficar musculoso. Não gostava de ir à academia, mas só assim fiquei respeitada e consegui continuar estudando: forte, parecendo um homem!".

O modo pelo qual o sistema educativo opera, inculcando como "naturais" e "universalmente legítimos" conteúdos arbitrários, constitui um elemento central da violência simbólica 27 . Ta noção não exclui a violência física, mas visa, sobretudo, fazer ver a objetividade da experiência subjetiva das relações de dominação, muitas vezes efetivadas em agressões físicas e psicológicas. A dominação masculina é um exemplo, por excelência, da submissão que decorre da violência simbólica 28 , e "feminilizar" outro homem é um modo de ser visto pelos pares com maior poder. A atribuição, na escola, do lugar de "veadinho" identifica essas crianças e adolescentes com o lugar do feminino moralmente discriminado, sendo, então, acusadas de serem "putas", o que justificaria toda a sorte de violência às quais estão submetidas em ambientes de sociabilidade com os pares geracionais, como a escola 29. Mesmo antes da transformação corporal, as travestis narram a experiência nas escolas, valendo-se de expressões como medo e pavor. As escolhas, estilos e modos de vida das travestis são utilizados para legitimar e rotinizar as violências contra elas.

À medida que suas escolhas vão se consolidando, as formas de violação vão se multiplicando. É uma constante o perambular das travestis, de um município para outro, em busca de moradias e trabalho ${ }^{30}$. O direito a uma casa e à convivência é violado em grande parte dos espaços disponíveis para locação.

A dissidência das normas heterossexuais é condenada na maioria dos itinerários percorridos pelas travestis. Os discursos religiosos e médico-científicos legitimaram instituições e práticas sociais baseadas em um conjunto de valores heteronormativos, os quais levam à discriminação negativa e à punição de diversos comportamentos sexuais, sob a acusação de crime, pecado ou doença 31 . A violência na vida das travestis é múltipla e normativa, resultado da interação de mudanças de representações culturais, experiência social e subjetividade individual 32 .

\section{Delegacia}

Todavia, uma das maiores experiências de sofrimento se dá quando a violência cotidiana é efetuada por instâncias que deveriam amenizá-la ou erradicá-la. O sofrimento social 22,33 está presente nas respostas aos problemas humanos por parte dasinstituições depolítica edos programas sociais que são, em princípio, organizados para sanálos. As ambiguidades das práticas institucionais voltadas para abrandar o sofrimento dos sujeitos tidos como excluídos e vulneráveis e que, paradoxalmente, resultam na sua intensificação 33 .

Existem, por exemplo, várias delegacias de polícia para delatar os casos de violência no Município de Santa Maria: da mulher, do idoso, da criança e adolescente. Para denunciar os 
diversos casos de violência contra as travestis, algumas procuram a Delegacia Geral, na região central do município (em teoria, destinada a esse fim). É comum não denunciarem as ofensas, pois, frequentemente, mesmo sendo vítimas, são transformadas em agressoras nos boletins de notificação. Luka, 24 anos, explica o motivo do silêncio: "todas sabem: ninguém acredita em travesti, então não adianta ir à delegacia fazer queixa".

Mesmo com iniciativas como a criação da Coordenadoria de Equidade e Gênero no município, no ano de 2007, são numerosos os relatos, como os da organização não-governamental (ONG) Igualdade no Coração do Rio Grande do Sul, que denunciam que as travestis e transexuais, além de sofrerem agressões constantes por parte de clientes, de familiares, na escola, no momento em que se dispõem a registrar queixa, sofrem preconceito e discriminação nas próprias delegacias. Uma das nossas interlocutoras, Gracy, de 29 anos, comentou sobre essa situação:

"Quando procuramos os serviços de saúde para realizar curativos ou mesmo a delegacia para denunciar as brigas, nos sentimos rejeitadas e discriminadas. Então, é comum nem darmos queixa, pois não dá em nada, no máximo, ainda sobra para nós, de novo!".

Na construção de Gracy, o deslizamento entre as instâncias é significativo. A delegacia e os serviços de saúde atuam da mesma forma e são interpretados como pertencentes a uma mesma máquina que reproduz a violência: "na delegacia ou numa UBS, é a mesma discriminação, o mesmo tratamento".

Apesar de avanços recentes na lesgislação de enfrentamento à violência de gênero, sobretudo após a aprovação da Lei $n^{\circ} 11.340$ (Lei Maria da Penha), em 2006, percebe-se que nem todas as questões que permeiam as assimetrias de gênero estão contempladas e efetivadas. Ao borrar as fronteiras de gênero tradicionais, as travestis acabam por sofrer a violência institucional nos espaços das delegacias. As Delegacias Especializadas no Atendimento à Mulher atuam como se as travestis fossem "menos mulheres", sequer considerando-as como sujeitos de direitos.

\section{Serviços de saúde}

Envoltas em violência na família, na escola e até nos espaços destinados a prevenir e impedir a violência, é natural que as travestis sintam, em seus corpos, as marcas da violência. Muitas situações narradas pelas travestis com as quais convivemos durante a pesquisa descrevem ferimentos, os quais necessitariam de curativos, aplicação de suturas, realização de radiografias para verificar a possibilidade de fraturas e mesmo pequenas cirurgias. No entanto, foi comum, em Santa Maria, elas evitarem os serviços públicos de saúde para esse atendimento. Em várias circunstâncias, narraram histórias de dores, seja por problemas clínicos ou situações de violência enfrentadas. Mas, mesmo em casos de dor intensa, evitam os serviços oficiais de saúde, sempre sustentando serem discriminadas nesses espaços 23 .

Em uma das visitas a um grupo de travestis durante o trabalho de campo, em março de 2012, Laysa, 23 anos, sentava com muita dificuldade em uma cadeira disposta na sala em que estávamos. Explicou que levara "umas facadas na nádega esquerda na noite anterior" e que não havia procurado o serviço de saúde, pois seria motivo de "chacota". Comentou então "prefiro ficar com dor e deixar a ferida colar sozinha em casa do que passar vexame no pronto-socorro".

Na maioria dos casos, os serviços de saúde não rompem o ciclo da violência simbólica contra as travestis. Uma vez que os profissionais de saúde não tiveram, em sua formação, ferramentas que lhes possibilitem compreender o universo travesti, é de se esperar que haja dificuldade no acolhimento e situações de constrangimento durante os atendimentos ${ }^{34}$. Esse é um dos aspectos de um amplo quadro de estigma, preconceito e abjeção envolvidos na situação de acolhimento das travestis nos serviços.

São muitas as dificuldades no atendimento à saúde das travestis nas instituições públicas de saúde: o mencionado desconhecimento dos profissionais de saúde dos problemas que afetam as travestis, a falta de resolutividade, a identificação pelo nome masculino no momento do atendimento, entre outros. As travestis sentem-se incomodadas pela forma como são tratadas, pelo julgamento moral e pela distância denunciada pelos gestos, olhares e falas dos profissionais que atendem nos serviços de saúde. Sobre isso, Thalya, 22 anos, comentou:

"Experimenta chegar ao serviço de saúde toda quebrada?! Já te olham de cima a baixo com uma cara de quem diz: ela merece isso mesmo! Ainda por cima exigem teu documento que está o nome masculino e gritam bem alto o teu nome de antes. Tem que levantar disfarçando que é tu. Já fica todo o mundo rindo".

Michelly, 28 anos, identifica, nos olhares e gestos dos profissionais, uma repreensão pelas suas escolhas:

"Eles olham para a gente e já pensam: onde já se viu estar vestida assim? Estão pedindo para apanhar, monte de bandidos, safados, veados![...] Sem contar o olhar das outras pessoas que estão esperando por atendimento. É como se não tivéssemos direito ao cuidado com a saúde!". 
Segundo nossas interlocutoras, uma das maiores violências dos serviços de saúde é denominarem as travestis pelo nome masculino. Ashley, 29 anos, manifesta seu descontentamento em um atendimento no serviço público de saúde:

"Outro dia, fui fazer meu teste anti-HIV, e a sala estava cheia de gente. Todo o mundo já olha atravessado, é como se tu já tivesse [AIDS], entende? Deixaram a porta aberta durante o atendimento. Levantei constrangida e tentei fechar a porta. Disseram para eu deixar a porta aberta. Pedi que colocassem meu nome de mulher no prontuário. Mas que nada! Passei o maior constrangimento quando me chamaram pelo nome de homem. Fiz de conta que não era comigo e saí disfarçada. Mas não adianta. Quem está ali percebe que é tu. Além disso, é um descaso, não resolvem o problema. Imagina, se o meu teste tivesse dado positivo para o HIV, eu não iria mais lá. É por essas e outras que as pessoas não se tratam".

Ser identificado publicamente pelo nome que não corresponde à aparência é uma violência responsável pela evasão das travestis dos serviços de saúde. Como nota o Grupo Pela Vidda 35 , é também a causa da evasão de mais da metade das travestis dos bancos escolares. O depoimento deVictoria também narra a heteronormatividade manifesta entre profissionais de serviços de saúde, reproduzindo a violência simbólica contra as travestis:

"Fui encaminhada para um ginecologista, mas ele me deu pílula só para se livrar de mim naquele dia. Foi bem grosseiro e disse que só entendia de ovários e vagina e que não conhecia mulher de pênis e barba. Que eu fosse procurar ajuda em outro lugar. Claro que não vou voltar lá, né?! Então, vou fazendo do jeito que dá. Vou juntando um dinheiro para uma hora colocar silicone e ficar com o corpo que eu desejo".

A experiência das travestis, em Santa Maria, mostra a atuação de serviços de saúde como reprodutores da violência social. Ao contrário de atuar combatendo a violência, cuidando e acolhendo integral e equanimemente, os profissionais classificam as travestis em categorias rígidas, heteronormativas, por meio de mecanismos complexos de patologização, criminalização e exclusão. Mostra também o abismo existente entre o plano jurídico e de efetivação de leis, resoluções e outras medidas que asseguram direitos às travestis.

A recusa em procurar os serviços públicos de saúde revela-se estratégia para lidar com a experiência de sofrimento social. Nas próprias palavras das nossas interlocutoras, elas evitam os serviços de saúde para não sofrerem "discriminação", "julgamento”, “chacota”, "humilha- ção", "constrangimento". A violência se revela na culpabilização das travestis pelas suas escolhas. Ao se revelarem espaços em que a violência simbólica 26 é reproduzida, os serviços de saúde contribuem na intensificação do sofrimento social das travestis.

Pesquisas 11,12 apontaram que a saúde das travestis é relegada à automedicação ou à ação de "bombadeiras". Em geral as "bombadeiras" são travestis mais velhas, que adquiriram experiência em injetar silicone industrial. A utilização de hormônios e silicone é amplamente debatida, e todas conhecem seus riscos. Alguns motivos são apontados para o silicone industrial ser a primeira opção: facilidade de acesso, custo menor do que cirurgia e não serem julgadas pelo procedimento.

Portanto, não apenas os agravos causados pelas situações de violência fazem com que as travestis necessitem de cuidados com a saúde. A própria construção do corpo da travesti exige cuidados especiais, já que pressupõe técnicas como a implantação de próteses de silicone nos seios e em outras partes do corpo (ordinariamente, efetuada por "bombadeiras") e a tomada de hormônios. Esse empenho na busca da feminilidade pode ter consequências desastrosas, tais como deslocamento do silicone para partes indesejadas do corpo (principalmente, pés e pernas), efeitos colaterais dos hormônios femininos. Não encontrar esse atendimento de forma integral no sistema de saúde é uma das maneiras de dar continuidade à violência.

\section{Considerações finais}

As diversas formas de violência vivenciadas nas trajetórias percorridas pelas travestis interferem diretamente nas suas condições de saúde. Além de distanciá-las da família nuclear e das relações de parentesco, retirando suporte material e relações afetivas, acabam por afastá-las, também, das escolas e dos serviços de saúde, que, como vimos, replicam a violência, conformando parte de seu sofrimento. Os efeitos são devastadores e, durante o trabalho de campo, acompanhamos casos de depressão, tentativa de suicídio, ferimentos e agravos dos mais diversos.

Ao contrário de localizar a violência como fenômeno homogêneo, as travestis de Santa Maria insistem na particularidade da violência por elas sofrida, apontando seu caráter de gênero. A violência é fruto de uma ordem moral, produzida e sustentada dentro de um quadro de relações de poder, que replica formações culturais, moldando, torcendo, dobrando e, frequentemente, fraturando a vida de pessoas. A experiência das travestis em Santa Maria revela como a violên- 
cia é crucial no processo social de legitimação, normatização e simplificação por meio das quais a heteronormatividade busca se impor à experiência de pessoas à margem das normas hegemônicas de gênero.

A violência simbólica se manifesta de maneira sutil, nem sempre é visível, porém, permeia as relações de desigualdades presentes em uma sociedade. Essa violência simbólica revela-se na família, na escola e, comumente, nos espaços públicos, em que, não raras vezes, classificam-se os sujeitos em categorias rígidas, por meio de mecanismos complexos de patologização, criminalização e exclusão. Ao ser replicada por instâncias que deveriam amenizá-la ou erradicá-la, como os serviços de saúde e as delegacias de polícia, os processos de violência simbólica atuam naturalizando as representações dominantes.

Em todas as situações etnografadas, nos casos em que há uma procura pelos serviços públicos, tais como as delegacias de polícia e serviços de saúde, a violência era replicada e formava parte agravante do sofrimento das travestis. É justamente por reproduzir a violência que deveriam conter ou amenizar que, como demostramos, as travestis, mesmo na presença de ferimentos graves ou com intensas dores físicas, dificilmente procuram as instituições públicas de saúde. Elas sabem, pela experiência nesses espaços, que terão dificuldades no atendimento e enfrentarão a indiferença, a humilhação, o julgamento moral e a baixa resolutividade. Como já mencionado, um dos maiores embaraços apontados é a identificação pelo nome masculino, o que demonstra, no mínimo, o desconhecimento de parte dos profissionais de saúde de Santa Maria da Política Nacional de Saúde Integral para a população
LGBT, a qual permite a identificação pelo nome indicado pela travesti.

O Ministério da Saúde previu, para o ano de 2014, a notificação dos casos de violência contra travestis no âmbito do SUS, no entanto, a nossa pesquisa em Santa Maria nos permite questionar: como ocorreu essa notificação se, como demonstramos, as travestis raramente frequentam os serviços públicos de saúde? As delegacias de polícia, por sua vez, quando procuradas pelas travestis, têm dificuldade de compreender as suas queixas, concebendo-as como culpadas pela situação em litígio ou pelo conflito. Nas delegacias, as travestis são responsabilizadas pela violência contra elas cometidas. O mesmo ocorre nos serviços de saúde. É por esse quadro que, após o término de nossa pesquisa, iniciamos agora uma nova etapa, com maior protagonismo das travestis no próprio processo de conhecimento e com a participação de profissionais de saúde, discutindo o cuidado e acolhimento nos serviços de saúde. Essa foi uma solicitação de algumas travestis no decorrer da pesquisa.

O quadro de violência e sofrimento social relatado neste artigo sugere o quanto ainda se tem que caminhar para que se possa romper com esse campo de violência. Talvez, um primeiro passo seja repensar a formação dos profissionais que atendem as travestis, principalmente, a formação dos profissionais de saúde. Quem sabe se multiplicarmos meios de debater temas como sexualidade, gênero e diferença, possamos facilitar $\mathrm{o}$ atendimento adequado de forma mais integral para as travestis, minimizando as situações de violência tais como as citadas ao longo deste trabalho. 


\section{Resumen}

Hemos llevado a cabo una investigación etnográfica con personas transgénero de Santa María, Río Grande do Sul, Brasil, durante el año 2012, a través de la observación participante, entrevistas semiestructuradas y seguimiento de su vida cotidiana. Durante este período, se observó que la violencia física y simbólica y el sufrimiento que resulta de ellos, eran invariables, una condición que tenían que hacer frente en sus carreras, en sus prácticas y actividades diarias. Este artículo describe el panorama de la violencia experimentada en la rutina de transexuales (familia, escuela, policía, servicios de salud), con el objetivo particular de entender cómo este tipo de violencia está relacionado con experiencias en el cuidado de la salud y cómo los servicios de salud reaccionaron a este tipo de situaciones de violencia.

Travestismo; Violencia; Homofobia

\section{Colaboradores}

M. H. T. Souza contribuiu no desenho do estudo, na condução da pesquisa de campo, na escrita e revisão. P. Malvasi, M. C. Signorelli e P. P. G. Pereira contribuíram no desenho do estudo, no referencial teórico-metodológico e na revisão do artigo.

\section{Referências}

1. Minayo MCS. A inclusão da violência na agenda da saúde: trajetória histórica. Ciênc Saúde Coletiva 2007; 11 Suppl:1259-67.

2. Scharaiber LB, D'Oliveira AFPL, Couto MT. Violência e saúde: estudos científicos recentes. Rev Saúde Pública 2006; 40 N Esp:112-20.

3. Deslandes SF. Frágeis deuses: profissionais de emergência entre os danos da violência e a recriação da vida. Rio de Janeiro: Editora Fiocruz; 2002.

4. Dahlberg LL, Krug EG. Violência: um problema global de saúde pública. Ciênc Saúde Coletiva 2007; 11 Suppl:1163-78.

5. Minayo MC. Violência social sob a perspectiva da saúde pública. Cad Saúde Pública 1994; 10 Suppl 1:7-18.

6. Minayo MC. Violência e saúde. Rio de Janeiro: editora Fiocruz; 2006.
7. Relatório sobre violência homofóbica no Brasil: ano de 2011. Brasília: Secretaria de Direitos Humanos, Presidência da República; 2012.

8. Carrara S, Vianna ARB. Tá lá o corpo estendido no chão: a violência letal contra travestis no Rio de Janeiro. Physis (Rio J.) 2006; 16:233-49.

9. Peres WS. Subjetividade das travestis brasileiras: da vulnerabilidade da estigmatização à construção da cidadania [Tese de Doutorado]. Rio de Janeiro: Universidade do Estado do Rio de Janeiro; 2005.

10. Silva H. Travesti: a invenção do feminino. Rio de Janeiro: Editora Relume-Dumará; 1993.

11. Pelúcio L. Nos nervos, na carne, na pele: uma etnografia sobre prostituição travesti e o modelo de prevenção da aids. [Tese de Doutorado]. São Carlos: Universidade Federal de São Carlos; 2007. 
12. Benedetti MR. Toda feita: o corpo e o gênero das travestis. Rio de Janeiro: Editora Garamond; 2005.

13. Kullick D. Travesti: prostituição, sexo, gênero e cultura no Brasil. Rio de Janeiro: Editora Fiocruz; 2008.

14. Gerhardt TE. Itinerários terapêuticos em situações de pobreza: diversidade e pluralidade. Cad Saúde Publica 2006; 22:2449-463.

15. Pinho PA, Pereira PPG. Itinerários terapêuticos: trajetórias entrecruzadas na busca por cuidados. Interface Comun Saúde Educ 2012; 16:435-50.

16. Souza MHT, Signorelli MC, Coviello DM, Pereira PPG. Therapeutic itineraries of transvestites from the central region of the state of Rio Grande do Sul, Brazil. Ciênc Saúde Coletiva 2014; 19:2277-86.

17. Noel G, Zucal JG. Notas para una definición antropológica de la violencia: un debate en curso. PUBLICAR - En Antropología y Ciencias Sociales 2010; VIII (IX):98-121.

18. Victora C, Knauth DR. Corpo, gênero e saúde: a contribuição da antropologia. In: Strey MN, Cabeda STL, organizadores. Corpos e subjetividade em exercício interdisciplinar. Porto Alegre: EdiPUCRS; 2004. p. 81-91.

19. Minayo MCS. O desafio do conhecimento: pesquisa qualitativa em saúde. São Paulo: Editora Hucitec; 2000.

20. Geertz C. A interpretação das culturas. Rio de Janeiro: Jorge Zahar Editores; 1978.

21. Kleiman A. The violences of everyday life: the multiples forms and dynamics of social violence. In: Das V, Kleinman A, Ranphele M, Reynolds P, editors. Violence and subjectivity. Berkeley: University of California Press; 2000. p. 226-41.

22. Liamputtong P, Ezzy D. Qualitative research methods. 22nd Ed. Melbourne: Oxford Press; 2005.

23. Souza M. Itinerários terapêuticos das travestis de Santa Maria/RS [Tese de Doutorado]. São Paulo: Universidade Federal de São Paulo; 2013.

24. Mott L, Cerqueira MF, Almeida C. O crime antihomossexual no Brasil. Salvador: Editora Grupo Gay da Bahia; 2002.
25. Das V, Kleinman A, Ranphele M, Reynolds P, editors. Violence and subjectivity. Berkeley: University of California Press; 2000.

26. Silva MMV, Bento B. Produção e negociação das identidades trans nas relações familiares em Natal-RN. História Agora 2014; 16:34-57.

27. Bourdieu P. La reproduction: éléments d'unethéorie du système d'enseignement. Paris: Minuit; 1970.

28. Bourdieu P. A dominação masculina. Rio de Janeiro: Bertrand; 2003.

29. Facchini R, França IL. Convenções de gênero, sexualidade e violência: pesquisa com participantes dos eventos do Orgulho LGBT de São Paulo - 2009. Latitude 2013; 7:11-30.

30. Carrieri SP, Souza EM, Aguiar ARC. Trabalho, violência e sexualidade: estudo de lésbicas, travestis e transexuais. Revista de Administração Contemporânea 2014; 18:78-95.

31. Prado MAM, Machado FV. Preconceito contra homossexualidades: a hierarquia da invisibilidade. São Paulo: Cortez Editora; 2008.

32. Das V. Fronteiras, violência e o trabalho do tempo: alguns temas wittgensteinianos. Rev Bras Ciênc Soc 1999; 14:31-42.

33. Kleiman A, Das V, Lock M, editors. Social suffering. Berkeley: University of California Press; 1997.

34. Muller MI, Knauth DR. Desigualdades no SUS: o caso das travestis é "babado"! Cadernos EBAPE. BR 2008; 6(2). http://www.scielo.br/scielo. php?pid=S1679-39512008000200002\&script $=$ sci arttext.

35. Grupo Pela Vidda/Centro de Referência e Treinamento DST/AIDS-SP. Diversidade revelada. São Paulo: Gráfica Stampatto; 2010.

Recebido em 18/Mai/2014

Versão final reapresentada em 26/Set/2014

Aprovado em 10/Nov/2014 